Motrivivência Ano XXIII, No 37, P. 98-144 Dez./2011

http://dx.doi.org/10.5007/2175-8042.2011v23n37p98

\title{
A EDUCAÇÃO FÍSICA E A ESCOLA ITINERANTE: DISCUTINDO A FORMAÇÃO DE PROFESSORES ${ }^{1}$
}

Vicente Cabrera Calheiros²

RESUMO

Este estudo procura analisar as contribuições da Pedagogia do MST à organização do trabalho pedagógico da Educação Física. Toma como foco central a experiência docente/ discente de um coletivo de estudantes da Escola de Educação Física da Universidade Federal do Rio Grande do Sul (EsEF-UFRGS) e professores formados pela mesma, na Escola Itinerante Che Guevara, no período entre 2008 e 2009, buscando estabelecer/ compreender relações desta área do conhecimento com a Pedagogia do MST.

Palavras chave: Educação Física, Pedagogia do MST, Formação de professores

\section{Introdução}

Este trabalho é fruto da experiência docente/discente de um coletivo de estudantes da Escola de Educação Física da Universidade Federal do Rio Grande do Sul (EsEF-UFRGS) e professores formados pela mesma, nos anos de 2008 e 2009, na Escola Itinerante (EI) Che Guevara, que localizava-se ${ }^{3}$ no Acampamento Jair Antônio da Costa no município de Nova Santa Rita.

Ele surge de questionamentos frente à formação de professores de Educação Física (EFI),

1 Este artigo é fruto do meu Trabalho de Conclusão de Curso (TCC), apresentado em Dezembro de 2010, na EsEF-UFRGS.

2 Especializando do Programa de Pós-Graduação do Centro de Educação Física e Desporto da UFSM, membro da Linha de Estudos Epistemológicos Didáticos da Educação Física (LEEDEF). E-mail: vicentecalheiros@hotmail.com

3 O acampamento se deslocou para outro município em agosto de 2009. 
eda organização do seu trabalho pedagógico a partir da Pedagogia do Movimento dos Trabalhadores Rurais Sem Terra (MST) ${ }^{1}$. Tais questionamentos são frutos desta experiência na $\mathrm{El}$, visto ser uma realidade invisível à universidade. Entendendo que nossa formação acadêmica

não leva em conta elementos sobre as diversidades culturais.

O currículo baseia-se essencialmente no contexto urbano e exclui da discussão, da problematização e da construção de metodologias, os contextos e grupos minoritários, tais como as iniciativas de educação popular, os movimentos sociais, o meio rural, entre outros (MACHADO RIBEIRO \& MARIN, 2009, p.79)

$\mathrm{Na}$ busca por compreender que contribuições a Pedagogia do MST pode fornecer à Educação Física, a partir da experiência deste coletivo, no intuito de instigar maiores discussões na área, construí este estudo perspectivando trazer à academia a importância de ampliar o olhar para as diversidades culturais existentes. Dessa forma, como problema orientador, formulei a seguinte pergunta: Que contribuições a Pedagogia do MST pode fornecer à formação de professores de EFI, assim como a organização do seu trabalho pedagógico?

No caminho para alcançar uma aproximação com a(s) resposta(s) frente meu problema de pesquisa, realizei uma breve analise histórica da educação e a forma como as classes dirigentes se apropriaram dela no sentido da manutenção do seu poder sobre a classe trabalhadora. Em seguida estabeleci uma relação entre a EFI e a El a partir da produção acadêmica da área. Após a discussão com a literatura, tendo construído o corpo teórico do trabalho, trago alguns elementos colocados pelos(as) colaboradores(as) a partir de entrevistas semi-estruturadas ${ }^{2}$, ou seja, a análise da prática docente/ discente esteve concentrada a partir das contribuições trazidas por estes. Selecionei para as entrevistas, três integrantes do coletivo ${ }^{3}$, tendo

1 Mais especificamente dos seus princípios filosóficos e pedagógicos.

2 Em função das normas para publicação desta revista, não tive como expor o capítulo dedicado ao debate frente as contribuições colocadas a partir das entrevistas. Para acesso a esta discussão, procurar em:CALHEIROS, V. C. As contribuições da Pedagogia do MST à organização do trabalho pedagógico da Educação Física. Monografia (Graduação). 2010.

3 Para maiores detalhes a respeito deste coletivo, procurar em: CALHEIROS, V. C. As contribuições da Pedagogia do MST à organização do trabalho pedagógico da Educação Física. Monografia (Graduação). 2010. 
como critério de seleção: a) ter participado de todas as reuniões do coletivo(planejamento e grupos de estudo), assim como, b) ter ministrado no mínimo três aulas na El. Estabelecendo a discussão entre a literatura e o material empírico.

Antes de iniciar a discussão, é importante colocar minha opção, como pesquisador, pelo método materialista histórico e dialético, ou seja, o método marxista, entendido enquanto concepção de mundo, método de análise e práxis. Neste sentido a escolha do tema de pesquisa quanto à aproximação com este referencial representam minha posição frente à realidade e à concepção do fazer científico. Ambas as escolhas me fazem assumir uma postura que perpassa a mera crítica a forma de organização da vida no sistema capitalista, entendendo a realidade social centrada no embate entre classes antagônicas. Compreendo, assim como Silva (2009, p.04), que este referencial teórico é, "alémde uma postura ou concepção ontológica de mundo, também um método, cujacaracterística central é a apreensão radical da realidade", buscando, dessa forma, uma transformação radical da estrutura social historicamente construída.

\section{A questão da educação.}

Roseli S. Caldart (2004), no seu livro intitulado Pedagogia do Movimento Sem Terra, nos dá uma rica contextualização histórica da luta do MST pela educação e constituição da escola. Aborda os elementos fundamentais da experiência de construção de uma pedagogia que fosse capaz de responder as perguntas feitas pela realidade dos seus assentamentos, acampamentos, de seus momentos de marcha, atos, ocupações, e diversos outros momentos educativos, para além da sala de aula. Buscaram em outras experiências pedagógicas um amparo teórico para que, junto com a prática diária do MST (geral e especifica), fosse possível estabelecer uma relação para a elaboração dos pilares centrais (filosóficos e pedagógicos) de sua educação e escola. Com relação ao aporte teórico, no inicio do Setor de Educação (MST-RS), entre os anos de 1987 a 1990, percebemos que pelos "registros da época a ênfase esteve no estudo de Paulo Freire e também de alguns pensadores e pedagogos socialistas: Krupskaya, Pistrak, Makarenko e José Martí" (CALDART, 2004, p. 262). Sua proposta dialoga entre as experiências da educação popular (BRANDÃO, 1984; PALUDO, 2001; RIBEIRO, 2010) e da educação socialista, entendendo que 
ambas se complementam (embora possuam lugares distintos na história), pois surgem do embate da luta de classes, se posicionando de forma contrária ao capital.

Compreendo que as relações humanas contidas no desenvolvimento histórico das sociedades, até hoje, é fundamentado nas lutas de classes (MARX \& ENGELS, 2003). Sendo a classe dirigente no capitalismo, a burguesia, que se apropria da venda da força de trabalho alheia e determina o valor da vida.

Importante colocar que conforme os diferentes processos históricos, diferentes relações sociais se estabelecem e estas não podem ser entendidas como únicas, insuperáveis, inquestionáveis, e sim como relações em constante transformação, visto que a burguesia foi a "classe oprimida sob o domínio dos senhores feudais" (MARX \& ENGELS, 2003, p.47), vindo a desempenhar "na história um papel extremamente revolucionário" (Op. cit., p. 47).

Para que esta classe se apodere cada vez mais do controle das relações sociais existentes, tendo em mente a perpetuação do controle político e econômico do Estado, é necessário se apoderar do processo de produção das mercadorias e, não menos importante, transformar as relações sociais em mercadoria. Neste sentido, obtiveram enquanto classe um excelente resultado, conseguindo fazer da dignidade pessoal um simples valor de troca. Cabe colocar que o nascente Estado, como a forma burguesa de organização social na tentativa de romper com os laços feudais, merece maior atenção, porém, frente ao enfoque deste estudo, não irei discorrer profundamente a respeito. Ele foi sendo construído tendo em mente, desde sempre, a separação entre as classes, sendo uma importante ferramenta para a manutenção da hegemonia burguesa. É necessário então pensar em uma nova estrutura social, e nesse caso é preciso construir uma educação para a crescente classe burguesa, e a margem deste projeto, uma educação para a classe trabalhadora e, assim, construir uma escola que represente tais interesses.

A educação, nesse processo, possui uma estreita relação com os interesses conservadores da burguesia, e segundo Bezerra (1980, p. 25) ela "é um componente conjuntural. As suas instituições se moldam e produzem o tipo de educação que corresponde ao jogo de forças do momento", buscando claramente a manutenção das relações que os colocam como classe dirigente. Pistrak coloca que

A tendência à manutenção do regime exige que se cultive nos cidadãos (ou nos vassalos) 
os sentimentos conservadores, isto é, a idéia de que a destruição das bases "constitucionais" equivale ao caos, à anarquia, à selvageria, ao desaparecimento da cultura e da civilização; numa palavra, à volta ao estado selvagem (2000, p. 171).

Dessa forma, tais interesses vêem a se refletir na escola, como nos afirma Pistrak ao dizer que ela "sempre esteve a serviço das necessidades de um regime social determinado" (Op. Cit., p. 29), sendo neste caso específico o capitalismo, e continua afirmando que "se não fosse capaz disso, teria sido eliminada como um corpo estranho inútil" (Op. cit., p. 29). A escola é fruto do desenvolvimento histórico das relações humanas e sendo uma instituição social, obedece as finalidades que the são determinadas."(...) A escola, portanto, não é um local ingênuo sob um sistema qualquer. Dela espera-se que cumpra uma determinada função (FREITAS, apud CAMINI, 2009, p. 92)", visto que ela foi erigida como forma central de transmissão dos conteúdos necessários, estipulados pelas classes dirigentes, para a manutenção hegemônica do seu domínio social. A escola foi eleita como ferramenta principal no/do campo educacional. Procurou-se, com isso, construir uma educação moral e religiosa a ponto de que os "futuros" trabalhadores viessem a respeitar a ordem social, ao invés de questioná-la. Ela cumpre a função histórica de internalizar nos indivíduos a aceitação de uma nova realidade social, centrada no controle do tempo em função das necessidades da máquina produtiva, a partir da sua organização interna, fundamentada na obediência dos alunos aos professores e, destes, aos ditames do capital. Buscando esclarecer esta afirmação, compreendo que foi necessária uma reestruturação no sistema educacional, ou seja, foi preciso inventar e reinventar a escola frente aos desdobramentos sociais frutos desta reestruturação produtiva encabeçada pela burguesia. Foram criadas escolas onde não existiam, reformuladas as existentes introduzindo a força toda a população infantil. Segundo Enguita (1989), a educação e a escola foram reorganizadas a ponto de que as salas de aula se transformassem no local apropriado para se acostumar às relações sociais do processo de produção capitalista. Transformaram a escola no espaço institucional adequado para preparar as crianças e os jovens para o trabalho.

Camini (2009) discute sobre a concepção de educação e escola capitalista, e coloca que ela construída na contradição. Sendo ela produto da luta de classe, esse 
processo não se deu de forma tranquila, com passividade por parte dos trabalhadores. A resistência existiu, e ainda existe. Para a autora, sua forma é capitalista e repleta de contradições, visto se confrontarem os interesses do capital por meio da regulamentação e controle do Estado, e os interesses da classe trabalhadora.

Sendo a burguesia a classe em ascensão, a partir das transformações que desencadearam na ruptura com o modo de produção feudal e a imposição do capitalismo, iniciando um processo de crescente industrialização e deslocamento da centralidade social do campo para a cidade, ou seja, "o capitalismo vai desestruturando o regime feudal de produção, constituído pela produção agrícola camponesa autônoma e pela produção artesanal, para instaurar o sistema de fábrica" (RIBEIRO, 1999, p. 09), transformando o camponês em trabalhador assalariado.

É de extrema importância então, formar diferentes cidadãos, um para ser dirigente e outro, para ser dirigido. A educação toma um papel central nessa construção, pois a ela cabe a função de internalizar nos indivíduos a "legitimidade da posição que Ihes foi atribuída na hierarquia social, juntamente com suas expectativas "adequadas" e as formas de conduta "certas", como mais ou menos explicitamente estipuladas nesse terreno" (MESZÁROS, 2005, p.44).

Nessa mesma direção, Ribeiro (1999) aborda as questões que estavam no centro dos interesses que desencadearam na concepção de educação e construção da escola. Segundo a autora esta foi

(...) concebida no interior de processos revolucionários de instituição de um novo modelo de produção - o capitalismo que precisa de operários alfabetizados e disciplinados, ou mais produtivos; de um novo modelo de sociedade - a burguesa - que precisa libertar-se da "autoridade" eclesial, colocando-se, nos negócios, em nível de igualdade com a nobreza e o clero; de um novo modelo de ciência - a físico-experimental - para fundamentar a criação de máquinas-ferramentas que imponham aos operários o tempo, a quantidade e a qualidade da produção; de um novo modelo de política - o Estado - que unifique feudos, delimite um território, centralize poder, elabore e aplique as leis que regulem a organização da sociedade civil; portanto, de uma nova educação - a escola pública - que, através do ensino da língua vernácula, da disciplina e da 
obediência às leis civis, forme o cidadão burguês e o operário (RIBEIRO, 1999, p. 08).

A burguesia, a partir das transformações sociais estabelecidas no desenvolvimento da luta de classe se apropria da educação para seu beneficio próprio, buscando elevar seu poder sobre os trabalhadores. Este entendimento da realidade social centrada no embate entre burguês/proletário ganhou peso na obra de K. Marx e F. Engels, entendendo-os como fruto das relações postas no capitalismo, visto que para Engels (2005, p. 42), o "proletariado nasceu com a Revolução Industrial produzida na Inglaterra, na segunda metade do século 18". É importante então uma releitura desses conceitos visto que, as relações existentes na América Latina, especificamente no Brasil, no desenvolvimento histórico da luta dos camponeses pela terra (reforma agrária) não cabe no conceito exposto acima, assim como também não possui as mesmas características européias, visto que o camponês, enfim, o campesinato brasileiro"tem características particulares - em relação ao conceito clássico do camponês - que são o resultado do enfrentamento de situações próprias da história social do país (...)" (CARVALHO apud RIBEIRO, 2010, p. 78). Neste trabalho entendo os movimentos sociais populares (rural/urbano), especificamente o MST, como

“o conjunto social de setores organizados das classes populares, cuja práxis se orienta, pela necessidade e desejo de melhorar as condições de produção e reprodução da própria existência e pela perspectiva, mais ou menos consciente, de construção de novos ordenamentos sociais, econômicos, políticos e culturais" (PALUDO, 2001, p. 45).

São, dessa forma, sujeitos políticos coletivos, "no sentido de sujeito coletivo que passa a participar dos embates sociais" (CALDART, 2004, p. 34).

\section{A Educação Física e o MST: aproximações}

Para que a Educação Física possa dialogar com a proposta pedagógica do MST, sendo esta uma proposta/experiência de embate contra o capital, é preciso compreender determinados pontos para que seja possível estabelecer tal relação. Neste sentido,buscando referencias a respeito da cultura corporal na Pedagogia do MST "começamos a vislumbrar seus sinais a partir da discussão travada pelo Movimento em torno da cultura" (CASAGRANDE, 
2003, p. 03). Nestes materiais, colocam seu entendimento de cultura, que segundo Bogo (2009, p. 21) é "(...) tudo o que o que fazemos para produzir nossa existência". Ou seja, cultura para o MST é tudo o que o ser humano pensa, faz e sente repetidamente para garantir sua existência. Salientando então que, para o movimento, cultura, trabalho e existência estão interligados.

Neste processo continuo de aprendizados, a partir da vivencia de diferentes situações ao longo da história, o ser humano foi construindo diferentes culturas, visto que tais relações são produzidas em lugares distintos, com determinadas condições que não existem em todos os lugares (BOGO, 2009). Dentre estes conhecimentos produzidos pela humanidade, a materialidade corpórea se coloca de forma determinante para nossa existência. Compreendo que "existe uma cultura corporal, resultado de conhecimentos socialmente produzidos e historicamente acumulados pela humanidade (...)" (COLETIVO DE AUTORES, 1992 p. 39). Neste sentido, alguns antropólogos e historiadores afirmam que o primeiro instrumento de trabalho do homem foi a mão. A partir de uma necessidade de sobrevivência, por exemplo, ter de atirar uma pedra ou usar um pedaço de pau para se defender de algum animal, percebeu que poderia, com suas mãos, realizar diversas outras ações como: caçar, pescar, lascar a pedra, construir cabanas e, é claro, garantir sua sobrevivência(COLETIVO DE AUTORES, 1992).

O ser humano concomitante aos processos de construção de sua corporeidade foi criando também diversas outras atividades, outros instrumentos, e através do trabalho foi adaptando a natureza às suas necessidades, transformando-a e se transformando ao mesmo tempo, construindo cultura e se construindo.

Trago aqui a discussão presente na Metodologia Critico-Superadora, que entende que a “Educação Física é uma disciplina que trata, pedagogicamente, na escola, do conhecimento de uma área denominada aqui de cultura corporal" (COLETIVO DE AUTORES, 1992 p. 61). Definindo a Cultura Corporal como aquela que busca

(...) desenvolver uma reflexão pedagógica sobre o acervo de formas de representação do mundo que o homem tem produzido no decorrer da história, exteriorizadas pela expressão corporal: jogos, danças, lutas, exercícios ginásticos, esporte, malabarismo, contorcionismo, mímica e outros, que podem ser identificados como formas de representação simbólica de 
realidades vividas pelo homem, historicamente criadas e culturalmente desenvolvidas (COLETIVO DE AUTORES, 1992, p. 38).

Faço a opção pela Metodologia Critico-Superadora por que compreendo que ela possui uma estreita relação com a proposta de educação do MST, nas questões que permeiam seu referencial teórico e, segundo Banhiuk (2003, p. 33) (...) "esta metodologia da Educação Física é propositiva, trazendo sistematizações do conteúdo da área e apontando com clareza, sua visão de mundo: calcada no materialismo histórico-dialético". Tais propostas se aproximam por buscar construir um conhecimento voltado para a classe trabalhadora, por se voltarem para a transformação social e por terem como ponto de partida, e chegada, a prática social. Entendendo que para que exista uma proximidade entre a Educação Física e o MST, é necessário uma leitura que ultrapasse a mera crítica e busque respostas, formas, de superá-la.

\section{O MST e a Educação Física: uma discussão a partir das fontes}

Para compreender o entendimento do MST sobre a Educação Física, é necessário recorrer aos seus materiais referentes à educação e escola. Neste caso, tomo como referencia o Caderno de Educação No 13 - Dossiê MST e Escola. Este material traz documentos e estudos entre 1990 e 2001, reunindo catorze textos. Sendo este um importante trabalho do movimento que tem por objetivo, entre outros, mostrar os caminhos percorridos na sua luta pela educação. É um movimento que luta, essencialmente, pela Reforma Agrária e ao longo de sua história vem incorporando novas frentes de luta. Entre estas, está à questão da educação. A sua forma de lutar, é através de marchas que muitas vezes percorrem grandes distâncias, diversos atos, ocupações que podem durar muitos dias, entre outros. Para todas estas ações é necessário um grande preparo físico e muita disposição dos seus militantes. Neste sentido, teoricamente, enxergam a EFI no sentido da preparação física para que possam suportar as demandas das suas frentes de luta.Isto fica mais claro quando colocam que

O que pretendemos é formar corpos e mentes saudáveis, com preparo físico, resistência e disposição para a luta, o trabalho e o lazer. Neste sentido, a recomendação é que os momentos de Educação Física sejam dedicados predominantemente para: ginástica (montar uma 
sequência fixa de exercícios que trabalhem todas as partes do corpo), caminhadas longas e cadenciadas, corridas, saltos em altura e distancia, corda, bastão, lançamentos, exercícios de relaxamento corporal e mental. Em relação aos jogos, pode-se aproveitar o espaço da disciplina para ensinar as regras e técnicas dos principais jogos recreativos e esportivos. Quanto à prática dos jogos, o melhor é que fique no espaço de lazer coletivo a ser organizado pelos próprios alunos (MST, 2005, p.149).

Importante compreendermos que o MST necessita que seus militantes tenham um preparo físico que os possibilite permanecer na luta, pelo tempo que for preciso. Isso não quer dizer que enxerguem a $\mathrm{EFI}$ como um mero rol de atividades práticas descoladas da realidade social. Fica evidente que buscam um preparo físico para que seus militantes tenham as condições de responder efetivamente as frentes de luta, porém, como colocado a cima, nem sempre a teoria responde pela prática. Percebo que o entendimento da EFI por parte do movimento não perpassa as discussões teóricas da área, no que diz respeito às distintas tendências. Dessa forma, quando chegamos ao acampamento nos posicionando de forma critica, nos utilizando dos elementos da cultura corporal de forma a questionar, criticar e refletir sobre a realidade social no sentido de sua superação houve uma mudança no entendimento. É importante colocar que isto ficou restrito aos educandos/educadores do Acampamento Jair Antônio da Costa. O MST não está livre de contradições, sendo esta, uma entre outras tantas.

\section{Contribuições da Pedagogia do MST à organização do trabalho pedagógico da Edu- cação Física}

A relação da educação e escola com a realidade é um ponto central para a Pedagogia do MST, visto que para o movimento significa que

(...) ao tratarmos de processos ou práticas educativas, seja em um sentido mais amplo ou no sentido mais restrito da educação escolar, estamos no âmbito da questão de como a humanidade se faz a si mesma, em cada lugar, em cada tempo histórico. Estamos discutindo o ser humano e como é possível conformá-lo a um determinado 
modo de ser no mundo (CALDART, 2004, p. 85).

É necessário que tenhamos a compreensão de como a humanidade faz a si mesma, ao longo da história, por isso a importância na relação dos conteúdos com a prática social, para que não fique apenas no campo teórico. "O eixo de elaboração da proposta pedagógica foi no início, e continua sendo hoje, a prática dos sujeitos Sem Terra, desdobrada em questões do cotidiano pedagógico, da escola e do Movimento" (Op. Cit.p. 263). Dessa forma é possível que o trabalho educativo construa a emancipação humana, que lute pela superação das relações opressoras colocadas no capital, sendo uma necessidade frente o grau de degradação das relações humanas e também dos recursos naturais.

A emancipação humana como necessidade histórica só pode ser entendida como uma necessidade frente a degradação crescente e cada vez mais profunda do meio ambiente; do desemprego presente; da diminuição da taxa de uso das mercadorias, do agudo desperdício tanto na produção, como no consumo; entre outras. (BAHNIUK, 2009, p. 69)

Nesta perspectiva busca-se trabalhar todas as capacidades humanas, neste sentido
(...) tem-se, então, uma formação que abarca todas as capacidades humanas ou que abarca todos os lados da mesma. Para darmos um exemplo prático (...), essa seria uma idéia contrária a uma formação que contemplasse apenas uma dessas capacidades ou, melhor dizendo, que não tenha como premissa a formação unilateralizada - caso da formação "técnica", da formação para o "mercado de trabalho" (...) (SILVA, 2008, p. 34).

Nossa formação acadêmica centra-se na compreensão unilateral, buscando a aquisição de competências e habilidades, voltada para atender as demandas do mercado de trabalho, pautada na formação de capital humano. Para especificar este processo, esta dualidade unilateral - omnilateral, Silva (2008, p. 44) coloca que.

A formação para aquisição de competências e habilidades, a formação técnica e instrumental - que nos faz "aprender a fazer", mas não proporciona o aprendizado sobre "como, por que, para quê e para quem fazer" -, a formação para o mercado de trabalho, a formação unilateralizada - voltada para o desenvolvimento de apenas uma das capacidades do ser humano (...). 
A partir do acima exposto por Silva compreendo que a educação, em poder dos capitalistas, busca o isolamento desta com a realidade a fim de não propiciar aos trabalhadores a aproximação com as condições subjetivas de se libertar. Freire (1987, p. 87) coloca que "nenhuma "ordem" opressora suportaria que os oprimidos todos passassem a dizer: Por quê?". Deixar às classes oprimidas uma educação que os ensine o "aprender a fazer", dialogando com Silva.

Ernesto, um dos colaboradores, quando questionado sobre as contribuições coloca que

São alguns pontos né. Primeiro é pela pedagogia do MST ter um viés claro de pautar a formação humana e não meramente a qualificação profissional como a gente vê hoje na universidade. A universidade nos forma numa perspectiva de qualificação profissional para nós, a gente ir pra escola e formar nesse sentido também né. Agora, a pedagogia do movimento não, a pedagogia do MST ela avança nesse sentido (...).

É um ciclo vicioso onde os professores são formados na lógica da qualificação profissional e vão para a escola formar os estudantes neste mesmo sentido, entendendo a educação fora da política, assim como, a escola como uma ilha na sociedade, que não sobre influências da luta de classes, sem procurar questioná-la.

Compreendo que o professor ensina para além dos conteúdos que trabalha com suas turmas, ensina com sua prática, por isso autores como Pistrak (2000), Caldart (2004) entre outros, trazem a importância de o professor ser um militante social. Frederico, outro colaborador, coloca que a partir dessa relação “(...) está ligado ao educador ser protagonista dos processos sociais mais amplos que estão acontecendo". É necessário ensinar os estudantes a questionar, a partir dos elementos contraditórios da realidade, é preciso ensinar os professores a questionarem. Outra colaboradora, Rosa, coloca que o “(..) que eu mais aprendi lá [na El] na verdade é o questionamento", aprendeu a dialogar, a enxergar no educando alguém em que seja possível estabelecer uma relação de troca de aprendizados e ensinamentos, constituindo o que Paulo Freire (1987) denomina de educação dialógica. Ernesto também entende dessa forma quando traz esse elemento do questionamento das

relações sociais colocadas né, tu questionar as relações sociais por que, bom, tu esta li- 
dando com o pobre, tu esta lidando com o extremo da pobreza, essa questão é muito forte quando se entende que vivemos num mundo em que metade da população é pobre, e o nível da produção que a gente tem hoje, o desenvolvimento das forças produtivas garantiriam alimentar, sei lá, o dobro da população que vive, mas a partir da perspectiva que se vive, não, não da para fazer isso, em vez de dar a bóia para os pobres, queima a bóia. Sem contar a própria lógica destrutiva. O MST, ele consegue trazer isso para a gente também, apresentar uma outra perspectiva de sociedade (...).

Somente através da aproximação com a realidade é possível compreende-los, para que esse entendimento saia da teoria e se estabeleça a relação com a prática. Sendo também necessária a aproximação com a política e segundo Frederico é importante "(...) ter essa valorização dos aspectos políticos e econômicos dentro da aula, não tentar isolar a sala de aula como se fosse um espaço, uma ilha que não estivesse ligada a mais nada".

A mudança na perspectiva frente ao papel da educação é um ponto central que a Pedagogia do MST traz, não somente para a formação de professores de EFI, mas sim a educação geral. A compreensão de que o trabalho docente é muito maior que o momento da aula, no sentido colocado por Freitas (1995).

Dessa forma, posso afirmar que a Pedagogia do MST contribui para a formação de professores e a organização do trabalho pedagógico da EFI no momento em que ela demonstra a real possibilidade da transformação na concepção da educação, do papel do professor/ educador, da ousadia em contrariar o projeto burguês de sociedade e propor uma educação como prática para a liberdade.

\section{Considerações Finais}

Sem o propósito de esgotar esta questão e sim a fim de colocar esta problemática no processo de discussão da área, procurei demonstrar, a partir do colocado pelos colaboradores em diálogo com a literatura, a fragmentação do conhecimento existente, visto que não se estabelece uma relação dos conteúdos com a realidade limitando a intervenção prática, na escola. Dessa forma contraponho esta com a Pedagogia do MST, sendo ela permeada pela realidade, sendo pensada a partir dos elementos contraditórios do modo de produção capitalista, na luta pela sua superação. Centrados 
na lógica da emancipação humana, pautados no entendimento da educação como um espaço para a formação humana, contribuem no sentido da compreensão da escola como um tempo de vida, e não somente como um tempo de preparação para a vida, sendo esta uma concepção voltada para a formação de mão-de-obra para a inserção no mercado de trabalho, atendendo as necessidades do capital.

Percebo que sua contribuição vemno sentido da transformação da perspectiva, na possibilidade do contato imediato com a realidade na qual estamos estudando para intervir. A compreensão de que o estudo é uma relação que parte da prática, se apoiando na teoria buscando instrumentalizá-la para que se alcance a superação dos problemas em questão. Também em função do diálogo com as diferenças culturais, se faz necessário o contato com diferentes realidades para além dos muros da universidade (campo, periferia e etc.), para além do comodismo acadêmico. É importante a construção de uma formação que dialogue com os elementos da realidade, devendo ser possível um processo constante de avaliação, buscando responder de forma efetiva as constantes transformações sociais, tendo o entendimento da luta pela sua superação. O currículo não é um processo estanque, da mesma forma que não pode ser alterado segundo os interesses individuais dos professores, e sim pautado no diálogo entre as partes interessadas, em consonância com o Projeto Político Pedagógico da escola.

A lógica do mercado não pode continuar estando acima das relações humanas e, como disse Freire (1996, p. 146) "A lógica de comércio não pode estar acima da liberdade do ser humano". Devemos perceber a forma como buscam pautar, sempre em primeiro lugar, a relação entre os seres humanos lutando contra o trabalho feito pela burguesia quando esta "fez da dignidade pessoal um simples valor de troca e no lugar das inúmeras liberdades (...) colocou a liberdade de comércio sem escrúpulos" (MARX e ENGELS, 2003, p. 48), pautando estas relações apenas em interesses comerciais.

\section{REFERÊNCIAS}

ALVARENGA, Ana Maria.A Formação do Professor: Possibilidades e Limites na Organização de um Plano de Trabalho Coletivo no Programa Nacional de Educação na Reforma Agrária. Disponível em: http://www.uff.br/aleph/ textos_em_pdf/a_formacao_do professor_na_reforma_agraria. pdf-Acesso feito em 13/11/2010 
BANHIUK, Caroline. Educação Física/cultura corporal inserida nas escolas atreladas ao MST: Limites e possibilidades. Monografia (graduação). Universidade Federal do Paraná UFPR. 2003.

BANHIUK, Caroline. Educação, Trabalho e Emancipação Humana: Um estudo sobre as Escolas Itinerantes dos Acampamentos do MST. In: Cadernos da Escola Itinerante - MST. Ano II - No 3 - Abril de 2009. Pesquisa sobre a Escola Itinerante: Refletindo o Movimento da Escola.

BEZERRA, Aída. As atividades em educação popular. In: BRANDÃO, Carlos Rodrigues (org). A questão política da educação popular. $5^{\circ}$ edição. 1980.

BOGO, Ademar. O MST e a Cultura.

3. ed. São Paulo: 2009

BRANDÃO, Carlos Rodrigues. Educação Popular. $2^{\circ}$ Ed. São Paulo: 1984

CASAGRANDE, Nair \& FERREIRA, Cristiane Russo. O processo de Trabalho pedagógico da Educação Física no Movimento dos trabalhadores Rurais Sem Terra (MST) - Em Busca da formação humana a partir da perspectiva crítico superadora. 2003.
CASAGRANDE, Nair. O Processo de trabalho pedagógico no MST: contradições e superações no campo da cultura corporal.220 f. Dissertação ( mestrado em Serviço Social)Pós Graduação em Ciências Sociais, Universidade Federal do Pernambuco(UFPE), Recife, 2001.

CALDART, Roseli Salete. Pedagogia do Movimento Sem Terra. 3. ed. São Paulo: Expressão Popular, 2004.

CAMINI, Isabela. Escola Itinerante: no caminho de uma nova escola. 1. ed. São Paulo: Expressão Popular, 2009.

COLETIVO DE AUTORES. Metodologia do Ensino da Educação Física. São Paulo: Cortez, 1992.

Escola Itinerante do MST: História, Projeto e Experiências. Cadernos da Escola Itinerante - MST, Ano VIII - n 1 - Abril de 2008.

FERNÁNDEZ ENGUITA, M. A face oculta da escola: educação e trabalho no capitalismo. Porto Alegre: Artes Médicas, 1989.

FREIRE, Paulo. Pedagogia do Oprimido. 17. ed. Rio de janeiro, Paz e Terra, 1987. 
FREIRE, Paulo. Pedagogia da Autonomia. Saberes Necessários à Prática Educativa. ed. Rio de janeiro, Paz e Terra, 1996.

FREITAS, Luiz Carlos de. Crítica da organização do trabalho pedagógico e da didática.7 ed. Campinas, SP: Papirus, 1995. 288 p.

MACHADO RIBEIRO, Gabriela; MARIN, Elizara C. Educação Física escolar: a ação pedagógica e sua legitimação enquanto prática social na Escola Itinerante do MST. In: Revista Movimento. UFRGS, vol. 15, n. 4, 2009, p. 63 - 82.

MARX, Karl. ENGELS, Friedrich.

Manifesto do Partido Comunista.

São Paulo, SP: Martin Claret, 2003.

MÉSZÁROS, István. A educação para além do capital. São Paulo, SP: Boitempo, 2005.

PALUDO, Conceição. Educação popular em busca de alternativas: uma leitura desde o Campo Democrático e Popular. Porto Alegre, Tomo Editorial; 2001. PISTRAK. Fundamentos da Escola do Trabalho. Ed. Expressão Popular. 2000.
RIBEIRO, Marlene. Movimento Camponês, trabalho e educação: liberdade, autonomia , emancipação: princípios/fins da formação humana. 1. ed. - São Paulo: Expressão Popular, 2010. RIBEIRO, Marlene. Movimentos sociais e educação: desafios a uma pedagogia para a emancipação humana. In: Encontro Paranaense dos Estudantes de Pedagogia (20: 2003 : União da Vitória). Educação: cidadania, inclusão e movimentos sociais, União da Vitória : Faculdade Estadual de Filosofia Ciências e Letras, 2003. p. 57-69.

RIBEIRO, Marlene. É possível vincular educação e trabalho em uma sociedade "sem trabalho"?. Revista da UCPEL, Pelotas, v. 8, n. 1, p. 5-17, jan./jun. 1999.

SILVA, Guilherme Gil da.Realidade e possibilidades da formação de professores de educação física na perspectiva omnilateral frente às Diretrizes Curriculares Nacionais. Monografia (Especialização). Faculdade de Educação da UFBA. 2008 


\begin{abstract}
This study attempts to analyze the contributions of Pedagogy of the MST to the organization of the educational work of Physical Education. It takes as its central focus the teaching experience / student of a collective of students from the School of Physical Education, Federal University of Rio Grande do Sul (UFRGS-ESEF) and formed by the same teachers, the Itinerant School Che Guevara in the period between 2008 and 2009 , seeking to establish / understand this area of knowledge relationships with the Pedagogy of the MST.
\end{abstract}

Keywords: Physical Education, Pedagogy of the MST, Teacher training

Recebido em: agosto/2011 Aprovado em: março/2012 